\title{
Bovine Cysticercosis in Cattle Slaughtered at Zeway Municipal Abattoir: Prevalence and its Public Health Importance
}

\author{
Hussein Bedu${ }^{1}$, Ketema Tafess ${ }^{2 *}$, Birhanu Shelima ${ }^{3}$, Desalegn Woldeyohannes ${ }^{2}$, Bemnet Amare ${ }^{2}$ and Afework Kassu ${ }^{2}$ \\ ${ }^{1}$ University of Gondar, Faculty of Veterinary Medicine \\ ${ }^{2}$ University of Gondar, College of Medicine and Health Sciences, Department of Microbiology, Immunology and Parasitology \\ ${ }^{3}$ Adami Tulu Agricultural Research Centre, Oromia, Ethiopia
}

\begin{abstract}
A cross-sectional study on bovine cysticercosis was conducted at Zeway municipal abattoir from November 2010 to March 2011 with the main objectives of determining the prevalence of cysticercosis in animals, taeniasis in human and estimates the worth of taeniasis treatment in Zeway/Batu town. Active abattoir and questionnaire survey and inventory of pharmaceutical shops were performed to accomplish the study. Out of the total 400 inspected animals, 12 animals had variable number of Cysticercus bovis giving an overall prevalence of $12(3 \%)$. Anatomical distribution of the cyst showed that the highest proportions of C.bovis cyst were observed in tongue $33(34.4 \%)$ followed by heart $27(28.1 \%)$, triceps $21(21.9 \%)$ and masseter muscle 15(15.6\%). A total of 96 C. bovis were collected during the inspection; out of these, $32(33.3 \%)$ were found to be live cysts while $64(66.7 \%)$ were degenerative cysts. Of the total 120 interviewed respondents, $68(56.7 \%)$ had contracted $T$. saginata infection at least once in their life time. Human taeniasis prevalence showed significant difference $(p<0.05)$ with habit of raw meat consumption, sex and use of latrine. Accordingly frequent raw meat consumers $(\mathrm{OR}=10.71,95 \% \mathrm{Cl}$ [1.54-74.42], male individuals $(\mathrm{OR}=2.15,95 \% \mathrm{Cl}[0.95-4.88]$ and non latrine users $(\mathrm{OR}=4.40,95 \% \mathrm{Cl}$ [1.58-12.45] had higher odds for acquiring taeniasis than occasional meat consumer, female and latrine users, respectively. An inventory of taeniacidal drugs from private pharmacies, rural drug venders, clinics and public health centers indicate that drugs worth of 110,560 Ethiopian birr was sold in the past one year (2009/10). Therefore, attention should be given for awareness creation for people not to consume raw meat and to use latrine to decrease the contamination of grazing areas.
\end{abstract}

Keywords: Bovine; Cysticercosis/Taeniasis; Ethiopia; Prevalence; Zeway Municipal Abattoir

\section{Introduction}

Bovine cysticercosis, parasitic Zoonoses, is a disease that affects the muscle of cattle and is caused by the metacestode stages of the human intestinal cestode, Taenia saginata [1]. It has a worldwide distribution and the prevalence is low in developed countries, being less than $1 \%$ in carcasses inspected [2] and very common in Africa reaching a level of $30-36 \%$ in Kenya, 20\% in Guinea, 18\% in Sierra Leone and 20\% in Cameroon [3].

Based on abattoir survey, the prevalence reports of bovine cysticercosis in Ethiopia showed variable results with localities. Relatively lower prevalence of $3.1 \%$ in central Ethiopia [4], 4.9\% in Gondar [5] and 7.5\% in Addis Ababa [6] were reported, while higher prevalences of 17.5\% in East shoa [7], 21\% in Nekemt [8], and 26.25\% in Hawassa were found [9]. However, countrywide study on prevalence of bovine cysticericosis is still very limited.

The clinical effect of cysticercosis on infected animals is generally not significant but it is economically important as it causes carcass condemnation arising from heavy infestation with the cysticerci of T.saginata as well as the cost of inspecting meat, the necessity to freeze or boil infected meat and losses may also occur from restriction of live animal and animal products [10]. In African continent an annual loss was reported to be USD 1.8 billion under an overall infestation rate of $7 \%$. In South America, where an overall infestation rate was estimated at $2 \%$, caused an annual loss of USD 428 million [11,12]. It is more important with regard to high economic losses due to the condemnation of heavily infected carcasses.

Taenia saginata occurs in the small intestine of human and the metacestode (Cysticercus bovis) is found in cattle. Most incidents arise as a result of direct exposure to proglottids shed from farm workers, but there have been some reports of large scale outbreaks resulting from sewage-contaminate feed or forage [13]. Globally, there are 77 million human carriers T. saginata of out of which about $40 \%$ live in Africa. The average annual loss due to taeniacidal drugs for treatment in Ethiopia was estimated to be 4,937,583.21 Ethiopian birr [5,8,14].

The epidemiology of bovine cysticercosis/human taeniasis various from one area to another so control measures appropriate in one area is not necessarily of value in another. Hence, it is essential to have adequate knowledge of the epidemiology of the disease before contemplating control programmes. Therefore, the aims of this study were to determining the prevalence of cysticercosis in animals, viability of cyst, taeniasis in human and estimate the worth of taeniasis treatment in Zeway/Batu town.

\section{Materials and Methods}

\section{Study area}

The study was conducted at Zeway municipal abattoir. Zeway is

*Corresponding author: Ketema Tafess, University of Gondar, College of Medicine and Health Sciences, Department of Microbiology, Immunology and Parasitology P.O.Box 196, Gondar, Ethiopia, Tel: +251-911-746258; Email: Ketema_taf@yahoo.com

Received August 28, 2011; Accepted September 21, 2011; Published September 26, 2011

Citation: Bedu H, Tafess K, Shelima B, Woldeyohannes D, Amare B, et al. (2011) Bovine Cysticercosis in Cattle Slaughtered at Zeway Municipal Abattoir: Prevalence and its Public Health Importance. J Veterinar Sci Technol 2:108. doi:10.4172/21577579.1000108

Copyright: (c) 2011 Bedu H, et al. This is an open-access article distributed under the terms of the Creative Commons Attribution License, which permits unrestricted use, distribution, and reproduction in any medium, provided the original author and source are credited. 
located at $7.58^{\circ} \mathrm{n}$ latitude and $38.43^{\circ} \mathrm{e}$ longitudes in the southern part of Oromia regional state situated in mid rift valley, $160 \mathrm{kms}$ south of addis Ababa and it has $1403.3 \mathrm{~km}^{2}$ of land inhabited by about 141,745 people of which more than $85 \%$ are living in the rural areas. All the farmers are subsistence, whose livelihoods depend mainly on mixed farming of crop and livestock. Agro ecologically, the area is categorized under the semi arid [15], with minimum mean temperature of $12.7^{\circ} \mathrm{C}$ and maximum mean temperature of $27.2^{\circ} \mathrm{C}$ with relative humidity of $60 \%$. The area has an altitude ranging between 1500 and 2000 meter above sea level. The average annual rainfall ranges from $650-750 \mathrm{~mm}$ and the distribution is highly variable between and within years. Vertisol is the predominant soil type with sand-silt-clay in the portion of 33:48:18; respectively, and has a ph of 7.88 .

Crop-livestock mixed farming system characterizes agriculture in the district. Livestock production continues to be the major economic activity and is still the status symbol for farmers in Adami Tullu district. Cattle, goats, equines, and chickens are important livestock species reared. Cereals and pulses; maize, haricot bean, teff, wheat barley and sorghum are grown under rain fed condition by peasant farmers.

\section{Study design and study animal}

The study was across sectional type in which active abattoir survey, questionnaire and drug shop inventory were conducted. Study populations were cattle presented to the abattoir for slaughtering and routine meat inspection conditions. From those animals that daily came to the municipal abattoir, study animals were randomly selected and routinely inspected for T.saginata cysticercosis. Animals slaughtered during this study were all male animals of local breed.

\section{Sampling method and sample size determination}

Sampling was conducted using random sampling method. The sample size was determined using a method recommended by [16]. In this study, $50 \%$ prevalence was considered as there was no similar previous study in the area. To calculate the sample size single proportion formula was utilized.

$\mathrm{n}=1.962 \times \mathrm{p}_{\exp }\left(1-\mathrm{p}_{\exp }\right) / \mathrm{d} 2$

Where $\mathrm{n}=$ required sample size

$\mathrm{P}_{\text {exp }}=$ expected prevalence

$\mathrm{d} 2=$ desired absolute precision

$\mathrm{n}=1.962 \times 0.5(1-0.5) /(0.05)^{2}=384$ animals. Actually 400 animals were sampled and inspected during the study period for the presence of $C$. bovis cyst to increase the precision of sample size.

\section{Active abattoir survey}

Active abattoir survey was conducted during detail meat inspection on randomly selected 400 cattle slaughtered at Zeway municipal abattoir. Before slaughtering and inspecting the animals, ante mortem inspection was carried out and the tag number of each animal was recorded. Ante mortem examination on individual animals was done for the assessment of body condition, age, sex, breed and their place of origin. During post mortem inspection, palpation of the organs followed by incision of organs was made to examine for the presence of C. bovis, according to the guideline by [16], for masseter muscle, deep linear incision were made parallel to the mandible; the heart was incised from base to apex to open the pericardium and incise also made in the cardiac muscle for detail examination. Deep, adjacent and parallel incisions were made above the point elbow in the shoulder muscle. Examination of the kidney, liver, and the lung was also conducted accordingly.
In positive cases the site, the density and nature of the cyst were recorded and transported to the Parasitology laboratory in Adami Tulu Agricultural Research Centre (ATARC) for confirmation of cyst viability. The cysts were incubated at $37^{\circ} \mathrm{C}$ using $40 \%$ ox bile solution diluted in normal saline for 1-2hrs. After this, the scolex was examined under microscope by pressing between two glass slides. The cysts were regarded as viable if the scolex envaginates during the incubation period at the same time the scolex was checked whether it is T. saginata metacestode or other based on the size of cysticercus, absence of hook on the rostellem of the envaginated cyst [17].

\section{Questionnaire surveys on taeniasis}

Identification of respondents for questionnaire survey was based on random selection of volunteers from Zeway town. The selection was based on different age, sex, and working conditions. Accordingly, 120 volunteer individuals were selected and interviewed. Questionnaire survey on the disease occurrence and risk factors was administered on those 120 volunteer respondents from whom pre-informed consents were obtained. The potential risk factors of taeniasis such as habit of raw meat consumption, age, sex, religion, occupation, educational levels, presence and usage of sanitary facilities especially toilet and knowledge of $T$. saginata were assessed. Specific questions regarding medical history related to traditional and modern taeniacidal drugs use, impacts of taeniasis and possible options were included in the questionnaire to estimate the risk factors association with taeniasis.

\section{Inventory of pharmaceutical shops}

Regarding the drug inventory, relevant information was gathered from volunteer pharmaceutical shops in Zeway town. Different human drug stores located in Zeway town were invented for the amount and cost of drugs sold for the treatment of human taeniasis. During the study; inventory was conducted on six randomly selected private pharmaceutical shops and one public health center existing in Zeway town. Accordingly, annual adult dose of taeniacidal drug sales (based on prescription and patient complaints) in 2009 and 2010 were gathered to analyze the socio-economic impacts of taeniasis in the area.

\section{Data management and analysis}

Abattoir, questionnaire and drug inventory data were recorded on preformed tally sheets and preliminary analysis was done in Microsoft Excel. The abattoir data were summarized and prevalence was calculated for the area. Anatomical distribution of C. bovis and cyst viability were tabulated. The questionnaire data was also summarized and analyzed to using SPSS version 15 to assess association of potential risk factors for taeniasis among different respondents using binary and multivariate logistic regression

\section{Results}

\section{Prevalence of bovine cysticercosis}

Of the total 400 animals inspected, 12 (3\%) animals were found positive for $C$. bovis at postmortem inspection. There was no statistically significant difference $(p>0.05)$ in prevalence of bovine cysticercosis between sex and origin of animals. The highest prevalence was observed from cattle of Arsi Nagelle 3 (3.75\%) followed by Bulbula 4 (3.3\%), Adama 1(2.6\%), Meki 2(2.5\%) and the least Batu 2(2.3\%) (Table 1).

\section{Anatomical distribution and viability of cysts}

Analysis of the active abattoir survey showed that there was a 
Citation: Bedu H, Tafess K, Shelima B, Woldeyohannes D, Amare B, et al. (2011) Bovine Cysticercosis in Cattle Slaughtered at Zeway Municipal Abattoir: Prevalence and its Public Health Importance. J Veterinar Sci Technol 2:108. doi:10.4172/2157-7579.1000108

Page 3 of 5

\begin{tabular}{|c|c|c|c|c|c|}
\hline Variable & No of animals inspected & No animal infected & prevalence & $\mathrm{X} 2$ & P-value \\
\hline \multicolumn{6}{|l|}{ Sex } \\
\hline Male & 340 & 10 & 2.9 & 0.027 & 0.87 \\
\hline Female & 60 & 2 & 3.3 & & \\
\hline \multicolumn{6}{|l|}{ Origin } \\
\hline Arsi nagelle & 78 & 3 & 3.8 & 0.435 & 0.980 \\
\hline Bulbula & 120 & 4 & 3.3 & & \\
\hline Adama & 38 & 1 & 2.6 & & \\
\hline Meki & 80 & 2 & 2.5 & & \\
\hline Batu & 84 & 2 & 2.3 & & \\
\hline Total & 400 & 12 & 3 & & \\
\hline
\end{tabular}

Table 1: Prevalence of bovine cysticercosis on the basis of age and origin.

\begin{tabular}{|l|l|l|l|l|}
\hline Organs affected & No. of affected animals & Percentage (\%) & No. of cysts recovered \\
\hline Tongue & 8 & 2 & 33 & Percentage (\%) \\
\hline Heart & 7 & 1.7 & 27 & 34.4 \\
\hline Triceps & 5 & 1.2 & 21 & 28.1 \\
\hline Masseter & 3 & 0.7 & 15 & 21.9 \\
\hline
\end{tabular}

Table 2: Frequency distribution of $C$. bovis in different organs and tissues of affected animals.

\begin{tabular}{|c|c|c|c|c|c|c|}
\hline Infested organs & No.of live cysts & $\%$ of live cysts & No.of dead cysts & $\%$ of dead cysts & Total & Percentage (\%) \\
\hline Tongue & 17 & 53.1 & 16 & 25.0 & 33 & 34.4 \\
\hline Heart & 10 & 31.1 & 17 & 26.5 & 27 & 28.1 \\
\hline Triceps & 3 & 9.4 & 18 & 28.1 & 21 & 21.9 \\
\hline Masseter & 2 & 6.2 & 13 & 20.3 & 15 & 15.6 \\
\hline Total & 32 & 33.3 & 64 & 67.7 & 96 & 100 \\
\hline
\end{tabular}

Table 3: Number of dead and live $C$. bovis cysts found in different organs of infested animals.

\begin{tabular}{|l|l|l|l|l|}
\hline \multirow{2}{*}{ Drugs } & \multicolumn{2}{|l|}{ Doses in year } & Total doses & Total cost \\
\cline { 2 - 4 } & 2009 & 2010 & 32,782 & 65,927 ETB \\
\hline Niclosamide & 17,948 & 14,834 & 22,814 & 23,430 ETB \\
\hline Praziquantel & 7,963 & 14,851 & 10,266 & 8,794 ETB \\
\hline Albendazole & 4,400 & 5,866 & 8,752 & 12,409 ETB \\
\hline Mebendazole & 4,972 & 3,780 & \\
\hline
\end{tabular}

Table 4: Annual taeniacidal drugs sold during 2009-2010 at different pharmaceutical shops.

\begin{tabular}{|c|c|c|c|c|c|c|}
\hline Variables & No. of interviewed & No. of infected & $\%$ of infected & Crude Odd ratio & Adjusted odd ratio & P-value \\
\hline \multicolumn{7}{|l|}{ Sex } \\
\hline Male & 62 & 42 & 67.7 & 2.5 [1.23-5.43] & 2.15 [0.95-4.88] & 0.06 \\
\hline Female & 58 & 26 & 44.8 & 1 & & \\
\hline \multicolumn{7}{|l|}{ Religion } \\
\hline Christian & 46 & 28 & 60.9 & $1.32[0.62-2.79]$ & & \\
\hline Muslim & 74 & 40 & 54.1 & 1 & & \\
\hline \multicolumn{7}{|c|}{ Habit of raw meat } \\
\hline High & 32 & 26 & 81.3 & $13.0[2.08-81.04]$ & 10.71 [1.54-74.42] & 0.008 \\
\hline Medium & 80 & 40 & 50.0 & $3.0[0.57-15.76]$ & 2.3 [0.39-13.51] & \\
\hline Less & 8 & 2 & 25.0 & 1 & 1 & \\
\hline \multicolumn{7}{|l|}{ Age } \\
\hline$>45$ & 10 & 10 & 100 & ------ & & \\
\hline $18-45$ & 84 & 48 & 57.1 & $2.13[0.86-5.25]$ & & \\
\hline$<18$ & 26 & 10 & 38.5 & 1 & & \\
\hline \multicolumn{7}{|c|}{ Educational status } \\
\hline Elementary & 34 & 22 & 64.7 & $2.56[0.87-7.51]$ & & \\
\hline High school & 62 & 36 & 58.1 & $1.93[0.74-5.04]$ & & \\
\hline College & 24 & 10 & 41.7 & 1 & & \\
\hline \multicolumn{7}{|l|}{ Use of latrine } \\
\hline Non user & 92 & 59 & 32.1 & 3.77 [1.53-9.28] & 4.4 [1.58-12.45] & 0.005 \\
\hline User & 28 & 9 & 64.1 & 1 & 1 & \\
\hline
\end{tabular}

Table 5: Prevalence of $T$. saginata in human population of Zeway/Batu Town. 
variation with regard to the anatomical distribution of cysticercus cysts in the organs inspected. As indicated in Table 2, the highest proportions of $C$. bovis cyst were observed in tongue (2\%), followed by heart $(1.75 \%)$, triceps $(1.25 \%)$ and masseter muscle $(0.75 \%)$. Of the total $96 \mathrm{C}$.bovis cysts collected during the study period $32(33.3 \%)$ were found to be a live while other $64(67.7 \%)$ were degenerative cyst (Table 3).

\section{Pharmaceutical inventories}

An inventory of Pharmaceutical shops was conducted in Zeway town. Estimates of yearly adult taeniacidal drug doses and its worth were collected through personal interview with individuals in charge of pharmacies and using their records for the year 2009 and 2010. This revealed a total of 74,614 adult taeniacidal drug doses were sold for a total worth of 110,560 Ethiopian Birr (Table 4). Niclosamide and Praziquantel were the most frequently sold drugs for the treatment of taeniasis, while Albendazole and Mebendazole were the least sold drugs.

\section{Questionnaire survey on taeniasis}

Of the total 120 interviewed respondents who participated in this study, $56.7 \%(68 / 120)$ had contracted T.saginata infection at least once in their life time, of which, $95 \%$ and $5 \%$ reported using modern drugs and traditional drugs, respectively. The majority of the respondent had an experience of raw meat consumption as a result of traditional and cultural practice. The multiple logistic regression analysis of the risk factors showed significance difference $(p<0.05)$ in the prevalence of taeniasis with raw meat consumers, use of latrine and sex. Accordingly frequent raw meat consumers $(\mathrm{OR}=13.0,95 \%$ CI [2.08-81.04], male individuals $(\mathrm{OR}=2.58,95 \% \mathrm{CI}[1.23-5.43]$ and non latrine users $(\mathrm{OR}=3.77,95 \% \mathrm{CI}[1.53-9.28]$ had higher odds for acquiring taeniasis than occasional meat consumer, female and latrine users, respectively, but there was no significance difference between age, religion and educational status of the respondents ( $\mathrm{p}>0.05)$ (Table 5).

\section{Discussion}

Taeniasis /Cysticercosis occur most commonly in the environments characterized by poor sanitation, primitive livestock husbandry practice and inadequate meat inspection and control. Bovine cysticercosis usually does not cause much morbidity or mortality among cattle, but it does cause serious economic problems in the endemic areas due to the condemnation of meat or down grading of carcasses $[18,19]$ contributing to constraint in food security and safety. The results of the present study also reflect both the economic and zoonotic importance of this disease, which is in agreement with the above statements.

The prevalence of $C$. bovis among the carcasses inspected at Zeway municipal abattoir was $3 \%$, which was slightly in agreement with the findings of [20] in central Ethiopia (3.11\%), [5] in Gondar (4.9\%), and [21] in Asella (2.7\%). This study revealed light infection among the inspected animals and this could be due to the practical limitations to the number of incisions allowed and many infestations could be undetected [18]. As gross mutilation lowers the marketability of carcasses and introduces contamination, owners do not allow multi incisions for the detail investigation. However, the present study showed lower prevalence than the findings of [6] from Addis Ababa (7.5\%), [22] from Debre Zeit (13.8\%), [7] from East shoa (17.5\%), [8] from Nekemt (21\%) and [9] from Hawassa (26,25\%). Conversely, lower prevalence than this was reported from developed countries, such as $0.26 \%$ in Croatia [23], 0.48-1.08\% in Germany [24] and $0.9 \%$ in Cuba [25]. Thus, T. saginata cysticercosis has more public health and economic significance in developing country like Ethiopia compared with developed countries. Problems associated with poor sanitary infrastructure, low awareness and improper disposal of sewage are major factors for higher prevalence of cysticercosis in developing countries. Improper removal and treatment of sewage, application of sewage sludge to fields and faecal contamination of feed and/or water by farm employees are possible sources of infection in the developed countries $[26,27]$.

In this study, there is no association $(\mathrm{P}>0.05)$ between, age, origin and the prevalence of Cysticercosis and this agrees with the reports of $[4,7]$ and in the case of origin this was also agrees with [14].One possible explanation for insignificance of variation might be due to the fact that most of the animals slaughtered in this abattoir were adult and have similar husbandry systems (the same type of livestock management) [9].

Regarding the anatomical distribution of the cysts in the intermediate host, many researchers come up with different results. [14,22] reported triceps as being frequently affected by the cyst, heart by Mulugeta (1997). However, the present study showed that the most frequently affected organ with the highest number of cysts was the tongue which is in agreement with the reports of $[7,8,28]$ on their respective working sites. The viability test of the cysts revealed that it was the tongue, which harbored the highest number of viable cysts (17.7\%), followed by heart (10.4\%), triceps (3.1) and masseter (2.1\%). The variations in anatomical distribution depend on a number of factors, such as blood kinetics and animals' daily activities. Any geographical and environmental factors affecting blood kinetics in the animal affect the distribution of oncospheres as well and hence the predilection sites during meat inspection [29]. More importantly, most of these organs, except the lung and diaphragm, are consumed raw or undercooked and could be a potential public health hazard in contracting taeniasis. For instance, there is a habit of consuming raw or undercooked tongue and rumen fold preparation known as 'milas senber' as well as raw liver, kidney or muscle consumption in Ethiopia.

Human taeniasis was a widespread health problem in the study area with prevalence of $56.7 \%$ and agrees with the findings of others, $64.2 \%$ by [1], $51.1 \%$ by [30] .Significant association was also observed between taeniasis prevalence and sexes of the respondents. The higher prevalence of taeniasis among male individuals could be due to economic reasons and cultural practices in that male do not prepare their dish at home, rather consume at restaurants and butcheries. The study also showed significantly higher prevalence of Taeniasis among individuals who often consume raw meat than those with less frequent raw meat consumers. This is similar to the finding of [1] who reported higher prevalence of Taeniasis among raw meat consumers. Significant association was also observed between taeniasis prevalence and use of latrine and being higher in non latrine users.

Human taeniasis has importance both in socio economical and health aspects. However, evaluation of the economic aspects is very difficult particularly in developing countries like Ethiopia, where infected people treat themselves with traditional herbal drugs. One of the possible sources of information to evaluate the financial loss is to carry out inventories of pharmaceutical shops, which may not reflect the actual economic impact of the disease. However, inventory of 7 pharmaceutical shops existing in Zeway town for the years 2009 and 2010 indicated that, a total of 74,614 adult taeniacidal drug doses with an estimated cost of 110,560 Ethiopian Birr. This indicated that taeniasis diminishes the household financial resources, which could be easily avoided by eating well-cooked meat and using toilets. 
Citation: Bedu H, Tafess K, Shelima B, Woldeyohannes D, Amare B, et al. (2011) Bovine Cysticercosis in Cattle Slaughtered at Zeway Municipal Abattoir: Prevalence and its Public Health Importance. J Veterinar Sci Technol 2:108. doi:10.4172/2157-7579.1000108

\section{Conclusion}

Taenia saginata is a public health economically important cestode parasite prevalent in Ethiopia. High prevalence rate is associated with raw and under cooked beef consumption, presence of backyard slaughtering practices, indiscriminate defecation, low level of public awareness and poor waste disposal. In this study the prevalence of bovine cysticercosis determined by the active abattoir survey was relatively lower than the reports by different researchers in different parts of the country. However, there should be a public awareness about the health and economic significance of the disease by strengthening of training with special reference to the danger of raw or undercooked meat consumption and use of toilets/latrines.

\section{Acknowledgements}

We would like to express our heart-felt thanks to Gondar University faculty of Veterinary Medicine for financial support and Zeway Abattoir workers specially Ato Hedato and Ato Girma (meat inspector) for their kind collaboration during the sample collection.

\section{References}

1. Taylor MA, Coop LR, Wall LR (2007) Veterinary Parasitology $3^{\text {rd }}$ ed. USA: Black Well publisher. pp. 121-123.

2. Onyango-Abuje JA, Nginyi J, Rugutt MK, Wright HS, Lumumba P, et al. (1996) Sero-epidemiological survey of Taenia saginata cysticercosis in Kenya. Vet Parasitol 64: 177-185.

3. Gebreab F (1995) Zoonotic Diseases in Ethiopia. Ethiopian society of Animal Production. Addis Ababa 32-36

4. Tembo A (2001) Epidemiology of Taenia saginata, Taeniasis/ Cysticercosis in three selected agro- climatic zones. MSc. Thesis, Faculty of Veterinary Medicine, Free University of Berlin, Berlin.

5. Dawit S (2004) Epidemiology of Taenia saginata taeniasis and cysticercosis in North Gondar zone, Northwestern Ethiopia. DVM Thesis. Faculty of Veterinary Medicine, Addis Ababa University: DebreZeit, Ethiopia.

6. Nigatu K (2004) C. Bovis: Development and evaluation of serological tests and prevalence at Addis Ababa Abattoir. MSc Thesis, Addis Ababa University, Faculty of Veterinary Medicine, Debre zeit, Ethiopia.

7. Hailu D (2005) Prevalence and risk factors for T. Saginata cysticercosis in three selected areas of eastern Shoa. M.Sc Thesis, Addis Ababa University, Faculty of Veterinary Medicine, Debre Zeit, Ethiopia.

8. Ahmed I (1990) Bovine cysticercosis in animals slaughtered at Nekemt abattoir. DVM Thesis, Addis Ababa University, Faculty of Veterinary Medicine, Debre Zeit, Ethiopia.

9. Abunna F, Tilahun G, Megersa B, Regassa A (2008) Bovine cysticercosis in cattle slaughtered at Awassa municipal abattoir, Ethiopia: Prevalence, cyst viability, distribution and its public health implication. Zoonoses and Public Health 55: 82-88.

10. Soulsby EW (1982) Helmiths, Arthropods and Protozoa of Domestic Animals $7^{\text {th }}$ ed. London: Bailliere Tindal.

11. Mann I (1983) Environmental, hygiene and sanitation based on the concept of primary health care as a tool for surveillance, prevention and control of taeniasis/cysticercosis. Current Publication in Health Research in tropics 36 : $127-140$

12. Fan PC (1997) Annual economic loss caused by Taenia saginata asiatica taeniasis in East Asia. Parasitol Today 13: 194-196.

13. Taylor MA, Coop LR, Wall LR (2007) Veterinary Parasitology $3^{\text {rd }}$ ed. USA: Black Well publisher. pp. 121-123

14. Fufa A (2006) Study on the prevalence of bovine cysticercosis at Awassa town and its Surrounding, southern Ethiopia. Addis Ababa University, Faculty of Veterinary Medicine, DebreZeit, Ethiopia.

15. MOA (Minister of agriculture) (1972) Meat Inspection Regulations. Legal Notice No-428. Negarit Gazeta. Addis Ababa, Ethiopia.

16. Thrusfield M (2005) Veterinary Epidemiology. $2^{\text {nd }}$ ed. Exford: Black Well Science tropics.
17. WHO (1983) Guidelines for Survellience, Prevention and Control of Taeniasis/ Cysticercosis. In Gemmel M, Matyas Z, Pawlowiski Z, Suolsby EJL, VPH/83.49: 207-238.

18. WanzalaW, Onyango AG, Kang KE, Zessin HK, Kyule MN, et al. (2003) Contro of Taenia saginata by post-mortem examination of carcasses. Aft Health Sci 3: 68-76.

19. Onyango-Abuje JA, Nginyi JM, Rugutt MK, Wright SH, et al. (1996) Seroepidemiological survey of Taenia saginata cysticercosis in Kenya. Vet Parasito 64: $177-185$

20. Tembo A (2001) Epidemiology of Taenia saginata, Taeniasis/ Cysticercosis in three selected agro- climatic zones. MSc. Thesis, Faculty of Veterinary Medicine, Free University of Berlin, Berlin.

21. Dessie S (1992) Economic significance of bovine fasciolosis, hydatidosis and cysticercosis at Assela municipal abattoir. DVM Thesis, Addis Ababa University, Faculty of Veterinary Medicine, Debre Zeit, Ethiopia

22. Getachew B (1990) Prevalence and significance of Cysticercus bovis among cattle slaughtered at Debre zeit abattoir. Addis Ababa University, Faculty of Veterinary Medicine, Debre Zeit, Ethiopia.

23. Zivkovic J, Velimirovic D, Dzaja P, Grabarevic Z (1996) Prevalence of Cystcercus bovis S.hermis.Measles with Particular References to Histopathological changes in Meat. Archiv Furlebensmittel Hygine 47: 66-68.

24. Abusier S, Epe C, Schnieder T, Kedein G, Kühne M (2006) Visual Diagnosis of Taenia saginata Cysticercosis during meat inspection. Parasitology Res 99: 405-409.

25. Sau'rez HM, Santizo RM (2005) Epidemiology of the Taenia saginata complex and C. bovis in Ciego De Avila province of Cuba. Rev Pathology Tropic 34 43-52.

26. Fertig DL, Dorn RC (1985) Taenia saginata cysticercosis in an Ohio cattle feeding operation. J Am Vet Med Assoc186: 1280-1284.

27. Frolova A (1982) Epidemiology of Taeniasis. Moscow: Zoonoses Contro Collection of Teaching Aids for International Training Course. V.II, Moscow.

28. Amsalu D (1989) Prevalence and economic significance of cysticercus bovis in animal slaughtered in Gondar meat factory.DVM Thesis, Addis Ababa University, Faculty of Veterinary Medicine, Debre Zeit, Ethiopia.

29. Gracey JF, Collins DS (1992) Meat Hygiene. $9^{\text {th }}$ ed. London: Balliere Tindal. 24-28 Oval Road, London NW17DX.

30. Regassa A, Abunna F, Mulugeta A, Megersa B (2008) Major metacestodes in cattle Slaughtered at Wolaita Soddo Municipal abattoir, Southern Ethiopia: Prevalence, cyst Viability, organ distribution and socioeconomic implications. Trop Anim Health and Prod 41: 1495-1502. 